$1-2012$

\title{
Coexistence Patterns of Two Invasive Thistle Species, Carduus nutans and C. acanthoides, at Three Spatial Scales
}

\author{
Emily S.J. Rauschert \\ Cleveland State University, e.rauschert@csuohio.edu \\ Katriona Shea \\ Pennsylvania State University - Beaver \\ Ottar N. Bjørnstad \\ Pennsylvania State University
}

Follow this and additional works at: https://engagedscholarship.csuohio.edu/scibges_facpub

Part of the Biology Commons, and the Weed Science Commons

How does access to this work benefit you? Let us know!

Publisher's Statement

The final publication is available at Springer via http://dx.doi.org/10.1007/s10530-011-9992-z

\section{Recommended Citation}

Rauschert ESJ, Shea K, Bjørnstad ON. 2012. Coexistence patterns of two invasive thistle species, carduus nutans and C. acanthoides, at three spatial scales. Biol Invasions. 14(1):151-64.

This Article is brought to you for free and open access by the Biological, Geological, and Environmental Sciences Department at EngagedScholarship@CSU. It has been accepted for inclusion in Biological, Geological, and Environmental Faculty Publications by an authorized administrator of EngagedScholarship@CSU. For more information, please contact library.es@csuohio.edu. 


\title{
Coexistence patterns of two invasive thistle species, Carduus nutans and $C$. acanthoides, at three spatial scales
}

\author{
Emily S. J. Rauschert - Katriona Shea • \\ Ottar N. Bjørnstad
}

\begin{abstract}
To better understand the competitive processes involved in invasion by congeners, we examine coexistence patterns of two invasive species, Carduus nutans and $C$. acanthoides, at three spatial scales. A roadside survey of $5 \times 5 \mathrm{~km}$ blocks in a previously identified overlap zone provided information about the regional scale. At smaller scales, we surveyed four fields of natural co-occurrence, quantifying the spatial patterns at the field scale by randomly placed $1 \times 1 \mathrm{~m}$ quadrats and at the smallest scale by detailing plant position within the quadrats. The patterns observed are strikingly different at the different scales. At the regional scale, there is positive local autocorrelation in both species but negative cross-correlation between them, consistent with previous surveys. However, at the field scale,
\end{abstract}

there is positive local autocorrelation in both species, and we generally see a positive association between the two species. At the plot scale, when excluding areas of joint absence, there is again a negative association between the two species. This pattern can also be seen at the field scale when excluding plots with joint absence. These results suggest that, at the scale of a field, the strongest factor determining location is aggregation in favorable habitats, which is a stronger force than the competition-induced segregation evidenced at small scales. Lottery competition for spatially aggregated safe sites thus appears to drive the patterns observed at the field scale, while the regional scale pattern may be a result of restricted natural dispersal and invasion history.

Keywords Carduus - Coexistence - Congeners · Competition $\cdot$ Scale dependence $\cdot$ Spatial pattern

\section{Introduction}

Two important related themes in ecology are development and maintenance of species patterns in space and time, and the consequences of spatiotemporal pattern for population and ecosystem dynamics (Levin 1992). Although larger spatial patterns, such as range limitations, are generally understood to be driven by climatic variables, biotic interactions are also thought to be important (Fitzpatrick et al. 2008; 
Fitzpatrick et al. 2007). Competition, dispersal and environmental heterogeneities can have significant effects on the spatial patterns observed in plants (Seabloom et al. 2005). In animals, it is well known that competition through behavioral interactions, such as aggression in ants, can lead to the exclusion of species from certain areas (Cole 1983).

Competition can lead to quantifiable effects on plant distribution and diversity (Goldberg and Barton 1992). Competition can slow the invasion of a new species even if the established species is an inferior competitor (Hart and Gardner 1997), and the distribution of a species in invaded areas may be quite different from predictions based on its native distribution due to the novel competitive environments experienced (Poll et al. 2009). Because they are sessile, plants cannot leave environments where they experience high levels of competition. It is their interactions with their immediate neighbors that are of most importance, thus the spatial distribution of neighbors can influence the degree of competition actually experienced (Pacala 1986).

Studies of negative associations in the distribution of ecologically similar species date back at least to Diamond's (1975) study of birds on islands off New Guinea, where he described a "checkerboard" pattern in species associations, in which ecologically similar species did not coexist on islands. Diamond argued that competition led certain pairs of species to not cooccur. In a study of many assemblages of stream fishes, Winston (1995) similarly found that morphologically similar species were less likely to co-occur, and that competition was the most likely explanation for this pattern. Wilson (1988) studied plant communities in New Zealand and found an excess of both negative associations and positive associations compared to those expected under null models. The excess of negative associations would suggest competition, although in their study it is not possible to exclude different habitat preferences as a partial explanation. In general, it is important to attempt to disentangle the roles that habitat preference and competition may play in determining spatial patterns.

Spatial heterogeneities in population abundances can arise from environmental and community factors and are usually spatially autocorrelated (Legendre 1993). Spatial covariances can be important in linking observed patterns with ecological processes (Bjørnstad and Falck 2001). Direct (resource) competition between species should lead to negative cross-correlations at small distances but possibly positive cross-correlations at greater distances, indicative of local spatial segregation but positive association at the scale of the size of favorable germination patches if species share environmental preference (Dale 1999). For example, in an experimental study of the development of spatial structure in an experiment in California grasslands, competition was found to cause spatial segregation between grass species (Seabloom et al. 2005). Within species, limited dispersal should cause species to have a locally aggregated pattern (positive autocorrelation). Environmental heterogeneities can thus cause aggregation within a species and either aggregation or segregation (negative autocorrelation) between species, depending on whether the species have the same or different habitat preferences. Indirect interactions between species, such as apparent competition, can operate at a different spatial scale than direct interactions, and can influence patterns in different directions. The resulting spatial structure can be studied by examining patterns of autocorrelation and cross correlations at different spatial distances, which can be described by spatial statistics such as correlograms or variograms (Legendre 1993). The net effect of all of these processes on the spatial structure can be predicted from spatially-extended population dynamic models (Bolker and Pacala 1999; Seabloom et al. 2005).

Spatial scaling is fundamental to ecology, and different patterns may be observed at different scales (Wiens 1989). It is important to study correlation at several scales, as a lack of autocorrelation at one scale does not imply that there is no autocorrelation at other scales (Legendre and Fortin 1989). For example, in a study of two Ulex spp., Bullock et al. (2000) found that apparent co-occurrences at larger scales disappeared at finer scales. The patterns that can be observed are limited by the scale at which they are studied; inappropriate studies of scale can lead to misleading conclusions about the system (Freckleton and Watkinson 2002; Wiens 1989).

Allen and Shea (2006) documented a striking distributional pattern consisting of strong spatial segregation on a large-scale study (extent: $50 \times$ $100 \mathrm{~km}$, resolution $5 \times 5 \mathrm{~km}$ ) in central Pennsylvania, USA of two congeneric invaders (see Fig. 1). Carduus nutans $\mathrm{L}$. and $C$. acanthoides $\mathrm{L}$. 
Fig. 12002 distributions of Carduus nutans L. and C. acanthoides L. Figure 1 shows the distribution of $C$. nutans and $C$. acanthoides in central Pennsylvania (redrawn from Allen and Shea (2006)). The species are highly segregated, and there are fewer populations of both species in the area of overlap

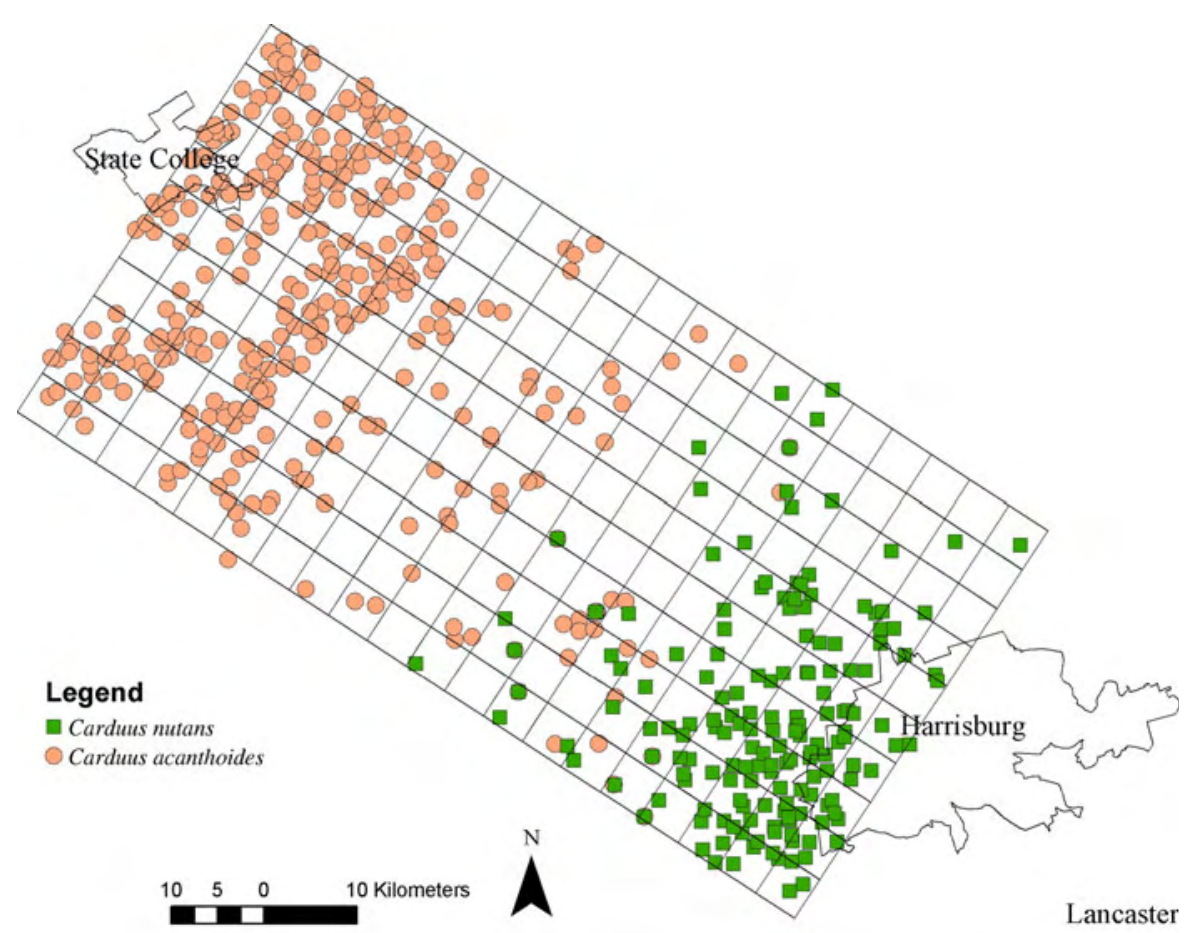

(Asteraceae) are thistle species from Europe and Asia, which have spread to become invasive species in the Americas, South Africa, Australia and New Zealand (Julien and Griffiths 1999). Both species are present in all cardinal directions away from Allen and Shea's (2006) study area; thus this is not an obvious case of non-overlapping range limits, nor do any environmental correlates explain this pattern. Allen and Shea (2006) propose several possible hypotheses to explain this distributional pattern, including competition between the two species; however, many of the mechanisms which could create such a pattern are hard to test at the coarse grain of their study.

In order to investigate the distributional patterns of Carduus nutans and C. acanthoides, we monitored the region of overlap identified in 2002 by Allen and Shea (2006) in 2004 and 2005 (regional scale). We also studied field-scale (intermediate) spatial patterns within four areas of natural co-occurrence, as well as within plot scale (fine scale, less than $1 \mathrm{~m}$ ) patterns within quadrats in these fields from 2003-2005. We analyze in detail the co-occurrence patterns of these species at these three levels of spatial resolution, and specifically ask the question whether or not the patterns of co-occurrence are consistent with the effects of direct competition between these two species.

\section{Methods}

Species description

Carduus nutans and C. acanthoides are both monocarpic perennials of Eurasian origin (Desrochers et al. 1988). They are difficult to distinguish morphologically at the rosette stages (Desrochers et al. 1988); however, pubescence on the underside of the leaf and leaf shape may be used to separate the species (McCarty et al. 1969). Vernalization is required for both species to bolt, after which their basal leaves decay. C. nutans grows to be approximately $2 \mathrm{~m}$ tall; C. acanthoides is generally slightly shorter, approximately $1.5 \mathrm{~m}$ tall (Rhodes and Block 2000) or taller (E. Rauschert, pers. obs.). Both species produce conspicuous purple flowerheads that are easily visible. When flowering, the species differences are most pronounced: $C$. nutans produces fewer, larger flowerheads and fewer stems, whereas $C$. acanthoides produces many small flowerheads and more stems.

In North America, $C$. nutans was first recorded near Harrisburg, PA in 1853, and C. acanthoides was first recorded in New Jersey in 1879 (Desrochers et al. 1988). Both occupy overgrazed pastures and disturbed roadsides. These species colonize new areas by seed 
dispersal; there is no record of vegetative reproduction (Desrochers et al. 1998). Individuals of both species can produce many thousands of seeds (Feldman and Lewis 1990; McCarty 1982) which are wind-dispersed. Studies of dispersal through seed tracking suggest that the two species disperse to similar distances, with estimates of mean dispersal ranging from 1.79-2.13 $\mathrm{m}$ for $C$. nutans and $1.60-1.99 \mathrm{~m}$ for C. acanthoides (Skarpaas and Shea 2007). C. nutans is also dispersed by water, birds and farm animals and vehicles; contaminated agricultural seed is an important mechanism of dispersal (Medd and Smith 1978). C. acanthoides is presumably also dispersed via such routes. Contaminated hay bales are a potentially important mechanism of localized, human-mediated dispersal for both species (D. Mortensen, pers. comm.). Skinner et al. (2000) rank C. nutans and $C$. acanthoides as the second and fifteenth most commonly listed noxious weeds in the US, respectively. Chemical, mechanical and biological control have been attempted with some success (Desrochers et al. 1988; Kok 2001; Kok and Mays 1991; Kok and Surles 1975; Sindel 1991).

There have been some reports of hybridization between the species (Hegi 1987; Moore and Mulligan 1956; Warwick et al. 1989); however, because C. nutans and C. acanthoides have different numbers of chromosomes, hybrids are almost completely sterile. There is also limited phenological overlap between the two species in Pennsylvania, thus most individuals observed were unlikely to be hybrids. Self-fertilization is common, with rates of up to $50 \%$ reported (Warwick and Thompson 1989).

\section{Survey methods}

Surveys were conducted at three spatial scales, as a multi-scale approach better allows an understanding of both the patterns and processes involved in invasions (Pauchard et al. 2003; Pauchard and Shea 2006). The spatial scales of the regional, field and plot surveys are summarized in Fig. 2. Extent and grain are specified, as both are important aspects of scale (Wiens 1989).

Regional survey methods

In order to monitor the stability of the regional distribution, the area of overlap was monitored in
2004 and 2005 using similar methods to Allen and Shea's 2003 survey (Allen and Shea 2006); we summarize the approach here. The survey area is a $100 \times 50 \mathrm{~km}$ area divided into blocks of 5 by $5 \mathrm{~km}$. Surveillance was done by driving along pre-chosen roads at a constant speed for $20 \mathrm{~km}$ per block in 2002, and $10 \mathrm{~km}$ per block in 2003. In 2004 and 2005, we surveyed blocks in the core 2002 areas of overlap. We surveyed 43 blocks in 2004 and 46 blocks in 2005. When a species was found, the location (using a Garmin ETrex Legend GPS unit), elevation, population size, abundance, spatial extent, road type, slope location (i.e. before, on or beyond the slope at the road edge), environment, slope and aspect were recorded. In contrast to Allen and Shea (2006), there was no "stopping rule"- all $10 \mathrm{~km}$ of each block were surveyed regardless of whether a species had previously been recorded in a given block. Moreover, unlike Allen and Shea (2006), we also recorded populations that were sighted within $2 \mathrm{~km}$ of the last population. These differences allow us to better estimate the densities of $C$. nutans and C. acanthoides populations in a block. Surveys were conducted when both species were flowering, as inflorescences can be seen from at least $100 \mathrm{~m}$ away (Allen and Shea 2006). In 2005, we also revisited all co-occurrence sites (14) that had been found in 2002-2004, to examine the short-term persistence of these mixed populations.

Field survey sites

Three of the sites identified as co-occurrences by Allen and Shea in 2002 were suitable for within-field surveying because they were accessible and had more than ten individuals of both species still present in 2003. We located a fourth site by driving in the area of overlap in 2003. All of these sites of overlap were located in Perry and Cumberland Counties in Pennsylvania. One site was an abandoned industrial site (Site I), two sites were permanent pastures (Sites P1 and P2) and one site was a long roadside over a forested ridge (Site R); these represent common habitat types for these species (Batra 1978). Both pastures chosen were permanent pastures, as rotations to tilling and cropping may break the cycle of biennials and perennials and obscure the co-occurrence patterns. Site descriptions are listed in Table 1. 
Fig. 2 Scales of study. Each square indicates an area studied. Each empty square represents an absence, red squares indicate $C$. acanthoides presence, green squares indicate $C$. nutans presence, and blue squares indicate presence of both species. At the field scale, we studied 4 fields of co-occurrence, and at the quadrat scale, we had between 180 and 320 quadrats in each site. The data shown (from 2004, Site I, Quadrat 63) are presenceabsence data

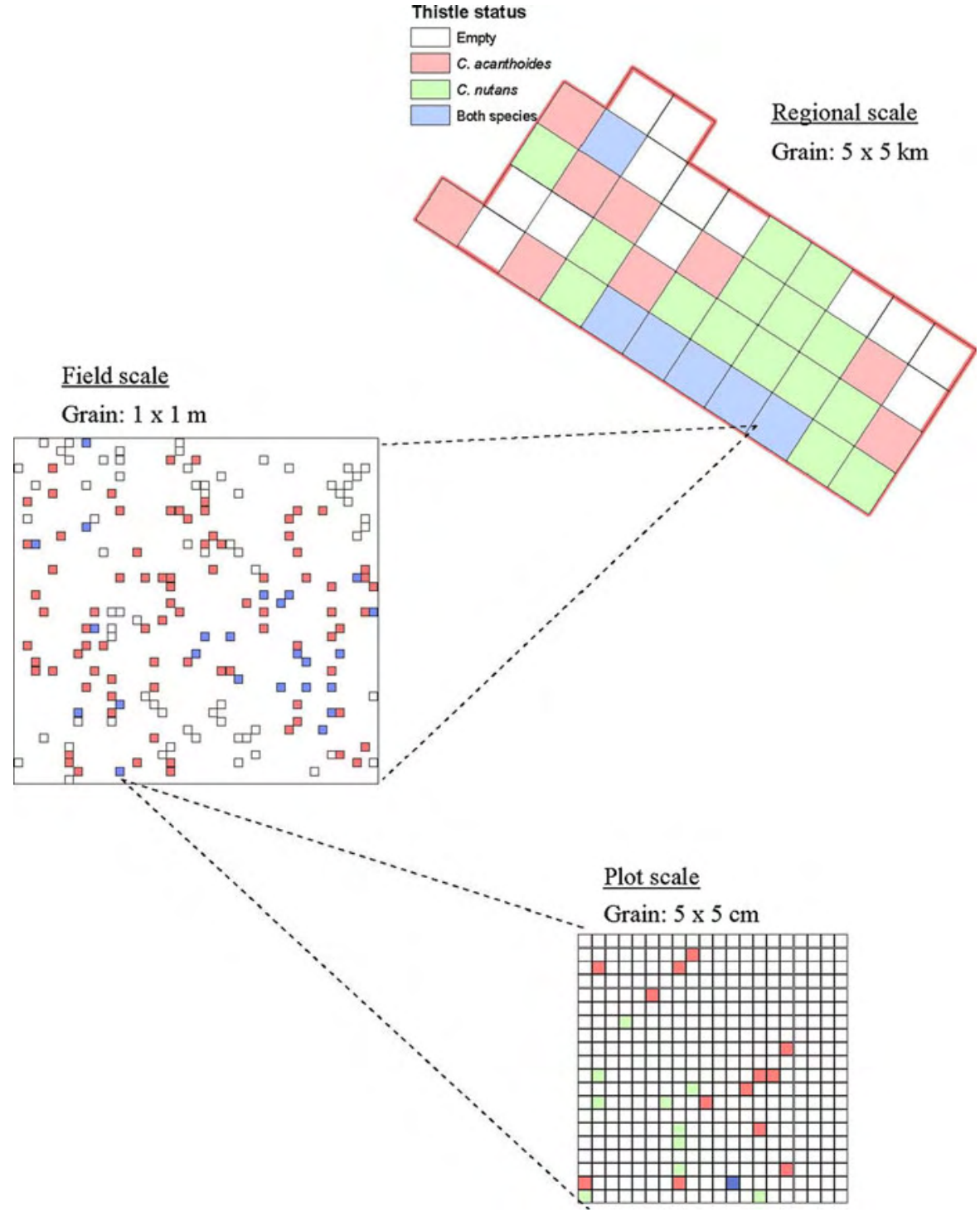

2004 and 2005 Field surveys

Fields were sampled using $1 \times 1 \mathrm{~m}$ quadrats covering at least $10 \%$ of the area of the field. In order to avoid problems of possible periodicity in the pattern (Krebs 1989), quadrat locations were chosen randomly each year. While re-randomizing between years does not allow us to track the fate of individuals, it does allow more independent estimates of the spatial pattern each year. Within a quadrat, the spatial location and species identity of each thistle was noted at a $5 \mathrm{~cm}$ resolution, giving spatial information at a yet finer scale. For flowering plants, the height of each individual and numbers of stems and flower heads were quantified. For rosettes, the longest leaf length was recorded; plant performance is size-dependent and longest leaf length is a good proxy for size (Kelly and Popay 1985; Shea and Kelly 1998). In 2004 and 2005, there were so few C. nutans individuals within the survey quadrats in P1 that it was decided to collect an extra dataset by centering quadrats on each $C$. nutans adult and surveying as usual; this extra dataset is referred to as P1X. 
Table 1 Field site descriptions

\begin{tabular}{|c|c|c|c|c|}
\hline $\begin{array}{l}\text { Site } \\
\text { name }\end{array}$ & Coordinates & Area & Species composition & Land use \\
\hline P1 & $\begin{array}{l}40.379 \mathrm{~N} \\
77.306 \mathrm{~W}\end{array}$ & $80 \times 30 \mathrm{~m}$ & Mostly Carduus acanthoides L. & Pasture: occasional cattle grazing \\
\hline $\mathrm{P} 2$ & $\begin{array}{l}40.225 \mathrm{~N} \\
77.431 \mathrm{~W}\end{array}$ & $\begin{array}{l}80 \times 25 \text { (main) } \\
45 \times 40 \\
(\text { middle })\end{array}$ & More even mix, still more $C$. acanthoides & $\begin{array}{l}\text { Pasture: daily cattle grazing, main } \\
\text { area near temporary stream }\end{array}$ \\
\hline I & $\begin{array}{l}40.183 \mathrm{~N} \\
77.238 \mathrm{~W}\end{array}$ & $45 \times 40 \mathrm{~m}$ & $\begin{array}{l}\text { Area surveyed had both species, side of field had } \\
\text { highest Carduus nutans L. density observed } \\
\text { anywhere }\end{array}$ & Abandoned industrial site \\
\hline $\mathrm{R}$ & $\begin{array}{l}40.301 \mathrm{~N} \\
77.400 \mathrm{~W}\end{array}$ & $\begin{array}{l}1,200 \times 1 \mathrm{~m} \\
\quad \text { (linear habitat) }\end{array}$ & $\begin{array}{l}\text { Top of slope had mostly } C \text {. nutans, lower areas } \\
\text { had mostly } C \text {. acanthoides }\end{array}$ & $\begin{array}{l}\text { Roadside along ridge through } \\
\text { Colonel Denning State Park }\end{array}$ \\
\hline
\end{tabular}

Analyses

All analyses were performed in R ( $\mathrm{R}$ Development Core Team 2010), and ArcGIS (ESRI 1999-2001) was used to visualize the larger scale data. Correlograms and cross-correlograms were used to analyze the spatial patterns of the thistle distributions at the regional and coarse-field scales. We are primarily interested in whether the correlations at the smallest distances are positive or negative, to assess whether there was evidence for competition between the two species. We term "positive autocorrelation" when autocorrelation at the smallest distance classes is positive, and "negative autocorrelation" when the autocorrelation at the smallest distances is negative, and similarly for crosscorrelations. In the case of cross-correlation, the former reflects association and the latter segregation. The significance of the correlation coefficients was calculated using a two-sided permutation test. A correlogram is considered globally significant if at least one correlation coefficient is significant at the level $\alpha^{\prime}=\alpha / v$ (Bonferroni corrected level), where $v$ is equal to the number of distance classes, and we consider the $\alpha=0.05$ level (Legendre and Fortin 1989). All correlograms were calculated using the "correlog" function in the "ncf" package in R (Bjørnstad 2009), which uses Moran's I for the correlation coefficients.

At the regional scale, we examined autocorrelation in block densities of populations (the number of populations of a species seen along a $10 \mathrm{~km}$ stretch of road in a $5 \times 5 \mathrm{~km}$ block) for both species, and cross-correlograms between the two species, using a binning increment of $10 \mathrm{~km}$. We only included blocks within the area of co-occurrence ( 32 blocks) in our analyses. We used a square root transformation of the density indicators to stabilize the variance in the data (Sokal and Rohlf 1995). We also examined autocorrelation and cross-correlation in block presence or absence of a species, in order to compare our results to those of Allen and Shea (2006).

At the field scale, we examined correlograms and cross-correlograms of the square-root transformed abundances. We examined autocorrelations in rosettes, flowering plants and all individuals for both species. For both auto- and cross-correlations, results for the rosettes, flowering plants and all individuals were similar, so we only present the results for all individuals. We also examined cross-correlations within a species between rosettes and flowering plants, which was generally similar to the autocorrelation results. P1 and P1X datasets were merged for this analysis. For each field, the distance classes were created using a binning increment of $2 \mathrm{~m}$. For Site R, we also present additional correlograms with a binning increment of $50 \mathrm{~m}$, in order to look at the pattern at the broader scales of the site (approximately 1,200 m long).

Often joint absences are not considered in such analyses, with the rationale that each species could be absent for different reasons (e.g. in a temperate forest, there are neither polar bears nor tropical birds, for reasons which do not indicate similarity). However, in this instance, the entire field is suitable climatically and in terms of soil characteristics, thus joint absence is still relevant. We present correlograms run both with and without co-absence to allow comparison with finer scale analyses. 
At the fine scale, we were unable to analyze the full dataset due to computation limitations in calculating correlograms with extremely large sample sizes. The data were subset to exclude areas of joint absence, which sufficiently reduced the sample size to allow the calculation of correlograms.

\section{Results}

Regional survey

The regional scale results (Fig. 3), showing a negative cross-correlation, were consistent with the findings of Allen and Shea (2006). The presence-
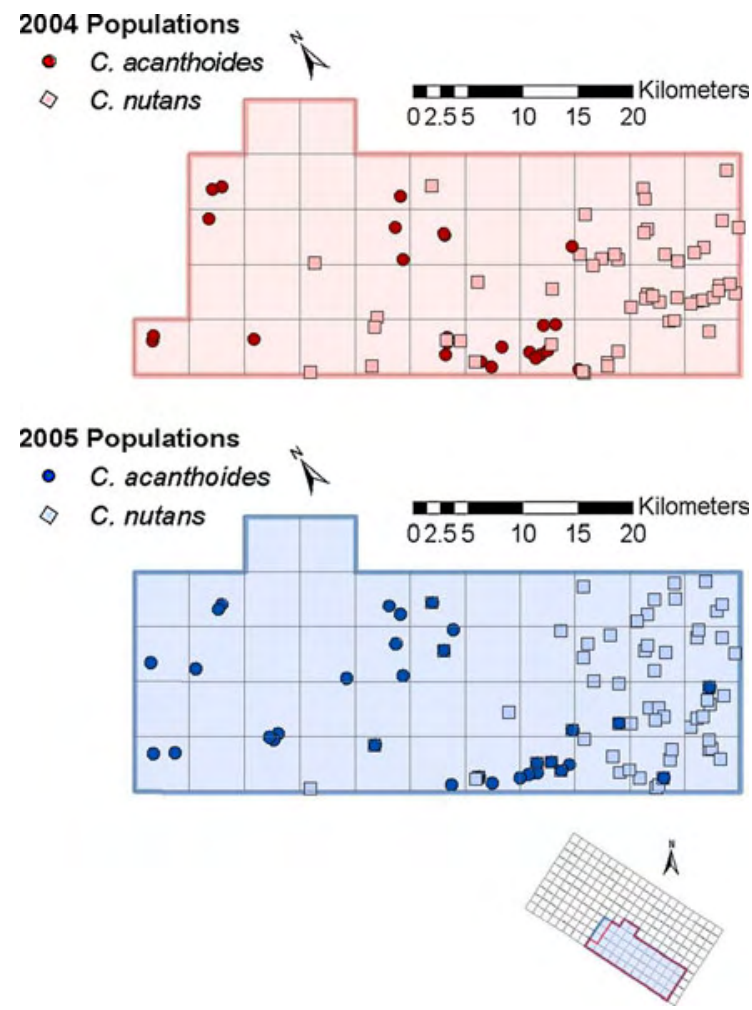

Fig. 3 Regional survey maps from 2004 to 2005. The area of overlap was resurveyed in 2004 and 2005. In 200443 blocks were surveyed; 21 contained $C$. nutans, 16 contained C. acanthoides and 6 contained both species (i.e. 12 had no thistle populations). In 2005, 46 blocks were surveyed; 20 contained $C$. nutans, 20 contained $C$. acanthoides, and 9 contained both species (i.e. 15 had no thistle populations). Of the 77 thistle sites identified in 2004 and 82 sites in 2005, there were 7 and 13 co-occurrence sites observed in 2004 and 2005 , respectively. The smaller map shows the relationship of our survey area to the larger area surveyed by Allen and Shea (2006) absence auto-correlograms (Fig. 4) were only globally significant for $C$. nutans in 2005, where positive autocorrelation was observed. The other three autocorrelograms suggest positive autocorrelation but are not globally significant. Density auto-correlograms (data not shown) reveal the same pattern.

Both the presence-absence and density cross-correlograms show negative cross-correlation at shorter distances and positive cross-correlations at longer distances. The spatial extent of negative correlations is smaller than that found by Allen and Shea (2006) for the full dataset, although subsetting their data to only include the blocks that we resurveyed leads to correlations similar to those we see (negative crosscorrelation up to $15-20 \mathrm{~km}$ ), and so is a function of the smaller extent of our surveys.

Of the 14 previously identified co-occurrence sites revisited in 2005, 3 had no flowering thistles, possibly due to management changes. Two sites had only C. acanthoides present, and one site had only C. nutans present. The nine other sites still had at least 10 individuals of both species.

Within-field surveys

There was considerable variation in the quadrat mean thistle densities, and the standard deviation was generally larger than the mean, indicating nonrandom patterns (Table 2). There were differences among fields and years: P2 generally had more thistles of both species (both flowering plants and rosettes) in 2005. Sites P1, I and R generally had more rosettes of both species in 2004 than in 2005; these fields had more bolting plants of both species in 2005 than in 2004, except Site R, which had more $C$. nutans flowering in 2005 than in 2004.

Significant positive autocorrelation within a species as well as positive cross-correlation between species are shown in the correlograms for Sites P1, P2 and I including joint absence quadrats, which show the overall pattern in the field (Fig. 5). This pattern was generally consistent regardless of whether just rosettes, just flowering plants, or all individuals of a species were considered. All correlograms are globally significant. The spatial scale of autocorrelation was generally similar, ranging between 10-20 m, with considerable variation seen. Cross-correlations between flowering plants and rosettes within a species were generally positive and were very similar to the autocorrelation 

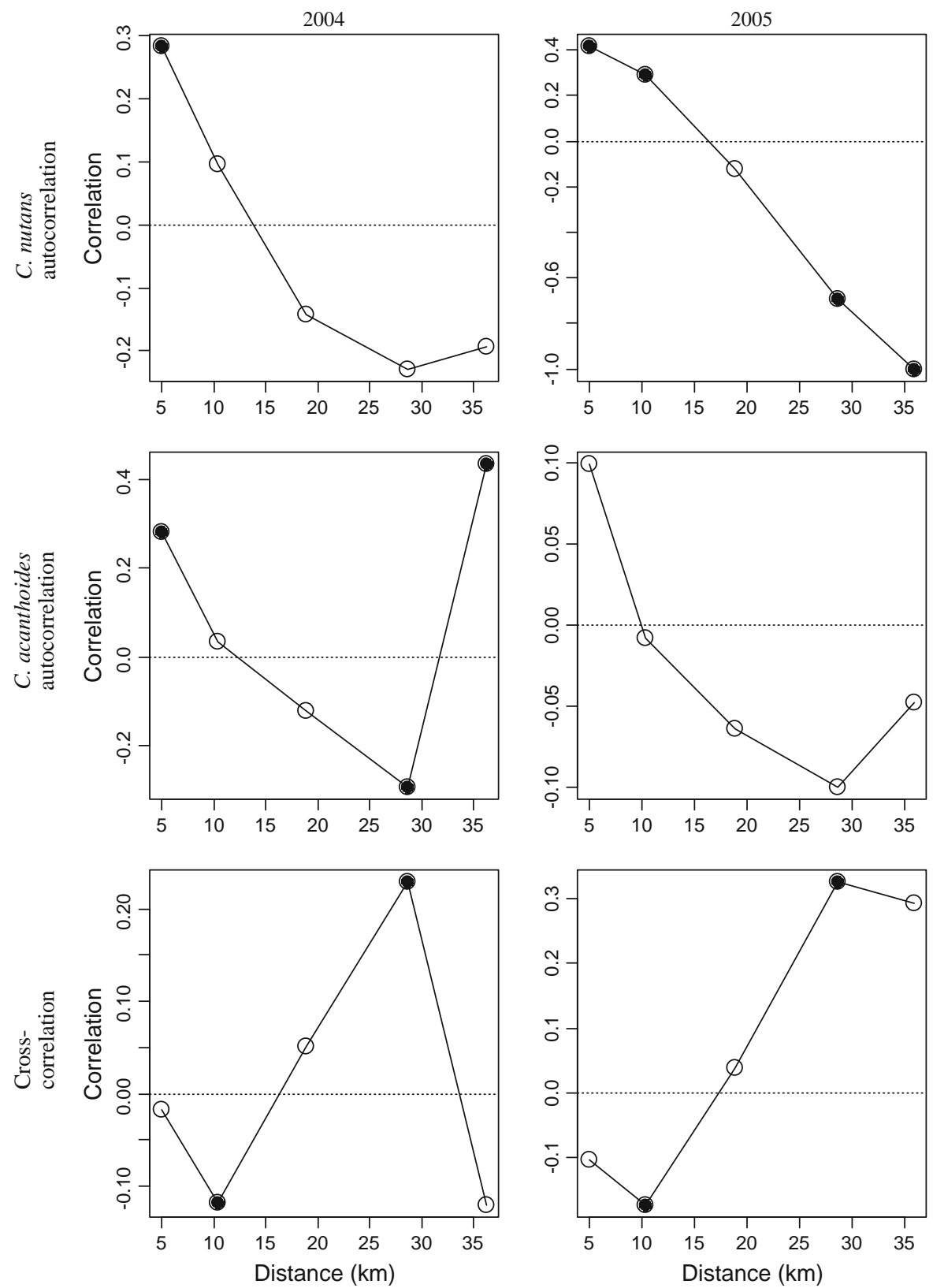

Fig. 4 Presence-absence correlograms from the regional survey. Correlograms show the correlations at various distances. Positive autocorrelation or cross-correlation occurs when correlations at the smallest distance classes are positive, and similarly for negative auto/cross-correlation. The filled dots indicate that a particular coefficient was significantly

results. However, Site R had a very different pattern (data not shown), perhaps because there were almost no quadrats of actual co-occurrence in this site. The top of the ridge tended to have $C$. nutans plants only, and the negative or positive. An increment of $10 \mathrm{~km}$ was used for these analyses. The 2004 autocorrelation correlograms are not globally significant, nor is the 2005 C. acanthoides autocorrelation correlogram. There is positive autocorrelation for each species but negative cross-correlation between species

lower portion of the ridge site tended to have C. acanthoides plants only. The correlograms of the smaller distances showed negative cross-correlation, but the coefficients were not significant. The autocorrelations 
were still positive. The larger distance correlograms of Site R (using a binning increment of $50 \mathrm{~m}$,) showed positive autocorrelation for both species, but the crosscorrelation was negative in both years.

When excluding the double-absence quadrats to examine the fine scale results, a very striking difference is observed in the cross-correlograms (Fig. 5). Whereas including the double-absence quadrats led to a positive cross-correlation, excluding them resulted in local negative cross-correlation in all fields in all years. This result is also observed when re-running medium scale correlograms ( $2 \mathrm{~m}$ binning increments) without including double-absence quadrats. The change in pattern is consistent with local competition for favorable germination sites.

In summary, we found different associations across the different scales (Fig. 6). Autocorrelation was positive for both species across scales, whereas cross-correlations varied at different scales. Negative cross correlation was observed at the regional scale, but the field scale revealed positive association between the two species. When examining a finer scale, only considering areas of fields where thistles occurred, negative correlation between the species is again apparent.

\section{Discussion}

The negative association between the two species at the regional scale appears to be consistent over the 4 years it was studied (2002-2005). These findings may suggest negative interactions between the two species, although abiotic factors are generally considered to drive distributions (particularly range limits) at larger scales (Levin 1989; Wiens 1989). It is known that both species co-occur at a larger scale: in North America, both species co-occur in 31 out of 48 states and five Canadian provinces (Allen and Shea 2006; USDA-NRCS 2010). However, at the scale of a field, we find positive cross-correlations between the two species when including all quadrats studied, which does not support the idea that there is strong competition between these species, leading to exclusion. In fact, these results are the opposite of what others have found (e.g. Bullock et al. 2000; Purves and Law 2002): instead of apparent co-occurrences disappearing at finer scales, we see apparent segregation disappear at finer scales. 
Fig. 5 Correlations at the field scale with and without joint absence plots. The filled dots indicate that a particular coefficient was significantly negative or positive. All correlograms were globally significant. The autocorrelation in both species is positive at both scales. The cross correlation is positive at the field scale ( $2 \mathrm{~m}$ binning increment) when considering joint absences; however, at the same scale excluding joint absences, there is negative cross correlation. This implies that the positive correlation is largely driven by both species not growing well in certain areas; underlying this is a weaker negative association, likely driven by competition or subtle habitat preferences. The data shown are from P1 in 2005; P2 and I are qualitatively similar
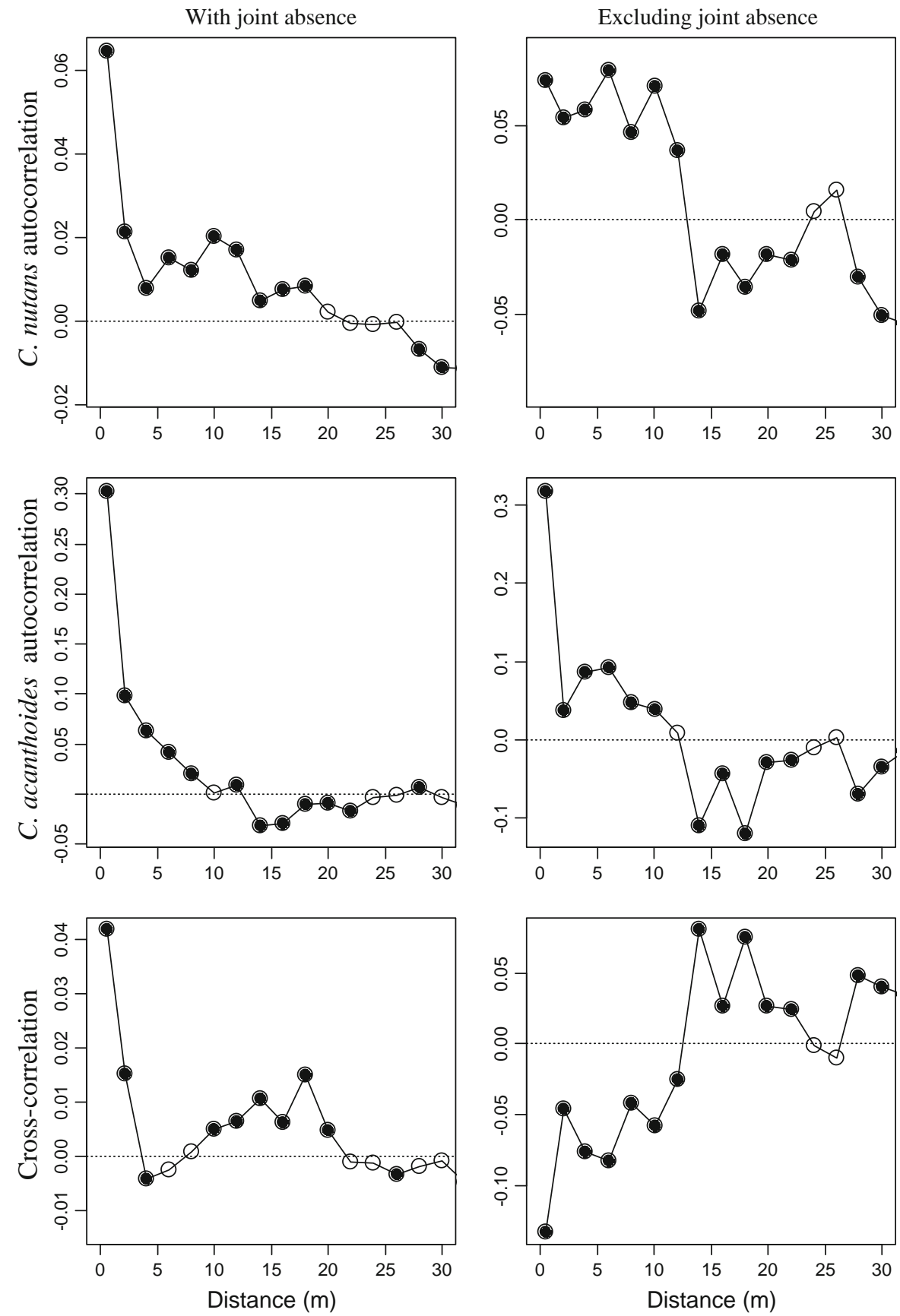

However, this difference appears to be largely driven by the fact that there are areas of the field in which neither species performs well. When we exclude these joint co-absence quadrats, we see negative cross correlation. At the finest scale (within-quadrats), there also appears to be a negative cross-correlation between species which re-emerges, indicating strong biotic interactions. These results highlight the importance of studying distributions at multiple scales and at scales relevant to the mechanisms under study (Wiens 1989).

The fact that we see both positive autocorrelation and positive cross-correlation (at similar scales) within a field when including all quadrats studied is 

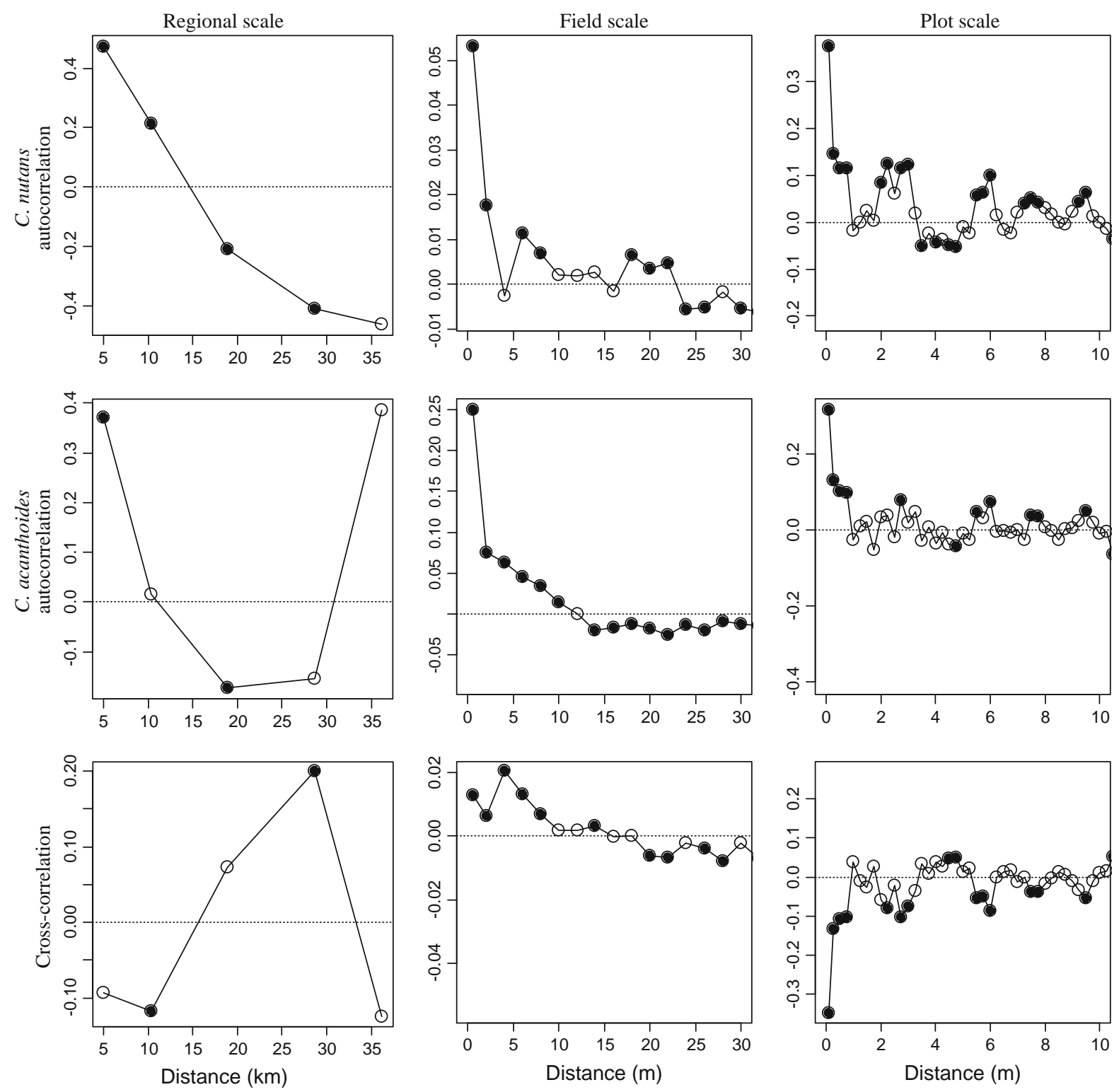

Fig. 6 Correlation across scales of study. Correlograms show the auto and cross-correlation at the three scales studied. Positive autocorrelation or cross-correlation occurs when correlations at the smallest distance classes are positive, and similarly for negative auto/cross-correlation. The filled dots indicate that a particular coefficient was significantly negative or positive. While autocorrelation in both species is consistently positive, cross correlations show a very different picture.

most consistent with the hypothesis that both species aggregate in favorable habitats. It may be that positive correlation in microsite suitability for germination induces the positive cross-correlation between these species; this effect is strong enough
At the regional scale, cross-correlation is negative; this is different at the field scale, where there is a positive association between the two species. At the finer scale, when excluding joint absences, a small-scale negative association is observed (data shown: 2004 regional density index, 2004 P1 data for field and fine scale). Results for the other three fields were similar, with the exception of Site R, likely due to its highly linear nature (along a roadside)

to outweigh the overall negative effects of competition. Thus the strongest competitive force at the scale of a field appears to be lottery competition to replace adults in favorable sites. The beneficial effects of being in good sites can be greater than the effects of 
competition with neighbors (Seabloom et al. 2005), particularly when patch quality varies in time (Fowler 1988).

Although this study was observational, making it generally more difficult to assign causality, the results of the pattern are consistent with the experiments of competition between these species (Rauschert 2006), which indicate that resource competition between these species does not appear to be very strong and that there are not strong differences between the species in terms of their competitive abilities. A companion study of the vegetation in the fields of cooccurrence found that there is a difference in the vegetation community between thistle quadrats and non-thistle quadrats, but that there are not strong differences between the quadrats occupied by $C$. nutans and C. acanthoides (Rauschert 2006). We also found significant spatial structure in the vegetation community, which further suggests that the fields are not homogeneous. A potentially valuable extension to this study would be to try to quantify the abiotic heterogeneities (such as soil texture or nutrients) in these fields. Once the heterogeneities to which the thistles are responding are known, it would be possible to account for them in the analysis, and see how the remaining pattern is distributed. In a study of aggregated congeneric fungi, Komonen (2005) found that once spatial clumping of suitable habitat was accounted for, the species distribution appeared to be random. A better understanding of the smaller scale environmental variation could be used to make predictions about where we might find thistles at larger scales. For example, Collingham et al. (2000) found that the same environmental variables that were important at a smaller scale $(2 \mathrm{~km})$ were also important at a larger scale $(10 \mathrm{~km})$ in their study of riparian weeds. These authors claim that it is possible to scale up within the same spatial extent, and it is possible to focus down from larger extents to smaller extents at the same resolution. Allen and Shea (2006) found no differences in habitat preferences of our two congeneric thistles at the regional scale. Our study suggests that they also prefer the same habitats at the field scale.

An important exception to the general pattern of positive cross-correlation at smaller scales was found in Site R. This site represents more of a transition between the regional scale and the field scale, since it is quite long (approximately $1 \mathrm{~km}$ ). The two species were not well mixed at this site, because the upper portion surveyed only had $C$. nutans, and the lower section only $C$. acanthoides. It is likely that these two species were introduced into this site when contaminated soil was brought in for the road edge; neither species is present for over a mile in either direction of the road, nor are they able to grow off the road in the forested areas. It is possible that soil from different areas, contaminated with different species, was used in sections of the road, leading to areas which only contain one species or the other, and that it is difficult in such poor habitat for the species to spread beyond the area of original introduction.

Seabloom et al. (2005), in an experimental grassland started from spatially random seeding, found that different processes (dispersal, competition, environmental heterogeneities) took different amounts of time to generate spatial structure during succession, and the spatial scale of the processes had different extents. Environmental heterogeneity caused aggregation in just 1 year at smaller spatial scales; dispersal and competition led to increasingly negative cross-correlation between species, which was not very apparent after 1 year, but became more apparent with time. Spatial patterns may sometimes develop quite rapidly; Stoll and Bergius (2005) found that competition led to regular spacing of plants within a five week experiment. The spatial segregation that develops from competition can be important in promoting coexistence of similar competitors, particularly if the scales of intra- and inter-specific competition are different (Murrell and Law 2003). In the areas that we studied, there should have been significant time for competition between the two species to leave a spatial signal: the two pasture fields that we studied were permanent pastures, and Site I appeared to have been managed similarly for at least the last 5 years. The signature of competition that we were able to observe was weak enough to be overridden by the effect of aggregation in favorable habitats.

As both of these species are of management concern, their movement and range expansion are of particular interest. Collingham et al. (2000) found that scale influences conclusions reached about whether or not a species had expanded and filled its potential range; larger (coarser) spatial scales were more likely to indicate that range expansion had ceased. Although these species occur across Pennsylvania, they are not found in all potentially suitable 
habitats (E. Rauschert, pers. obs.). Their projected invasion wave speeds, caused by natural dispersal, calculated using data collected in Pennsylvania, are very low: for $C$. acanthoides it is approximately $3 \mathrm{~m}$ per year, and for $C$. nutans is approximately $10 \mathrm{~m}$ per year (Skarpaas and Shea 2007). It is obvious that they have not moved across the state in less than 200 years via wind dispersal: presumably humans have moved them to areas far from the original introductions, but they may still be slowly filling in areas in between. Thus, it is possible that their current regionally segregated distribution is a historical artifact, which will decay over time.

$C$. nutans and $C$. acanthoides had markedly different spatial relationships at the three scales at which we studied them: segregation at a larger scale, aggregation at a medium scale and segregation at a fine scale. This is counter to the pattern that has been seen in other species. It is possible that such relationships are more likely to be seen for invasive species as compared to native species. At larger scales, invader presence may be primarily due to human activities, and may be due to human-mediated invasion history. At finer scales, their interactions with each other, with resident species and local habitat heterogeneity, as well as local disturbance regimes, may lead to quite different patterns of association. Caution should be taken when concluding that particular processes are unimportant, given that the scale of study can influence whether or not effects are observed. Given the slow natural spread of many species, it may take a very long time for natural small scale processes to influence large-scale distributions.

Acknowledgments This research was partially supported by USDA-CSREES (Biology of Weedy and Invasive Plants) NRI grant \#2002-35320-1228 to KS and a NASA Space Grant Fellowship to ER. We wish to thank Zeynep Sezen and Olav Skarpaas for support throughout the project, two anonymous families for the use of their fields and John Mellon, Jeff Butterbaugh, Elizabeth Dlugosz, Adam Reese, Stephen Selego and Gabby Hrycyshyn for field assistance. Eelke Jongejans, Zeynep Sezen and Olav Skarpaas provided useful comments on the manuscript.

\section{References}

Allen M, Shea K (2006) Spatial segregation of congeneric invaders in central Pennsylvania, USA. Biol Invasions 8:509-521

Batra SWT (1978) Carduus thistle distribution and biological control in the northeastern states. In: Frick KE (ed)
Biological control of the genus Carduus in the United States-a progress report, pp 18-22, science and education administration, US. Department of Agriculture, Washington, DC

Bjørnstad ON (2009) ncf: spatial nonparametric covariance functions. $\mathrm{R}$ package version 1.1-3. http://CRAN.Rproject.org/package $=$ ncf

Bjørnstad ON, Falck W (2001) Nonparametric spatial covariance functions: estimation and testing. Environ Ecol Stat 8:53-70

Bolker BM, Pacala SW (1999) Spatial moment equations for plant competition: understanding spatial strategies and the advantages of short dispersal. Am Nat 153:575-602

Bullock JM, Edwards RJ, Carey PD, Rose RJ (2000) Geographical separation of two Ulex species at three spatial scales: does competition limit species' ranges? Ecography 23:257-271

Cole BJ (1983) Assembly of mangrove ant communitiespatterns of geographical-distribution. J Anim Ecol 52: 339-347

Collingham YC, Wadsworth RA, Huntley B, Hulme PE (2000) Predicting the spatial distribution of non-indigenous riparian weeds: issues of spatial scale and extent. J Appl Ecol 37:13-27

Dale MRT (1999) Spatial pattern analysis in plant ecology. Cambridge University Press, Cambridge

Desrochers AM, Bain JF, Warwick SI (1988) The biology of Canadian weeds 89. Carduus nutans L. and Carduus acanthoides L. Can J Plant Sci 68:1053-1068

Diamond JM (1975) Assembly of species communities. In: Cody ML, Diamond JM (eds) Ecology and evolution of communities, pp 342-444. Belknap Press of Harvard University Press, Cambridge, MA

ESRI (1999-2001) ArcGIS Desktop, Version 8.3

Feldman SR, Lewis JP (1990) Output and dispersal of propagules of Carduus acanthoides L. Weed Res 30:161-169

Fitzpatrick MC, Weltzin JF, Sanders NJ, Dunn RR (2007) The biogeography of prediction error: why does the introduced range of the fire ant over-predict its native range? Glob Ecol Biogeogr 16:24-33

Fitzpatrick MC, Dunn RR, Sanders NJ (2008) Data sets matter, but so do evolution and ecology. Glob Ecol Biogeogr 17:562-565

Fowler NL (1988) What is a safe site-neighbor, litter, germination date, and patch effects. Ecology 69:947-961

Freckleton RP, Watkinson AR (2002) Large-scale spatial dynamics of plants: metapopulations, regional ensembles and patchy populations. J Ecol 90:419-434

Goldberg DE, Barton AM (1992) Patterns and consequences of interspecific competition in natural communities-a review of field experiments with plants. Am Nat 139:771-801

Hart DR, Gardner RH (1997) A spatial model for the spread of invading organisms subject to competition. J Math Biol 35:935-948

Hegi G (1987) Carduus distel. llustrierte Flora von Mitteleuropa, Paul Parey, Berlin

Julien MH and Griffiths MW (1999) Biological control of weeds: a world catalogue of agents and their target weeds. 4th edn

Kelly D and Popay AI (1985) Pasture production lost to unsprayed thistles at two sites.In: Proceedings of the 38th 
New Zealand weed and pest control conference. pp 115-118

Kok LT (2001) Classical biological control of nodding and plumeless thistles. Biol Control 21:206-213

Kok LT, Mays WT (1991) Successful biological control of plumeless thistle, Carduus acanthoides L. [Campanulatae: Asteraceae (=Compositae) by Trichosirocalus horridus (Panzer) (Coleoptera:Curculionidae) in Virginia. Biol Control 1:197-202

Kok LT, Surles WW (1975) Successful biocontrol of musk thistles by an introduced weevil, Rhinocyllus conicus. Environ Entomol 4:1025-1027

Komonen A (2005) Local spatial pattern in the occurrence of two congeneric wood-decaying fungi in an old-growth boreal forest. Scand J For Res 20:393-399

Krebs CJ (1989) Ecological methodology. Harper \& Row, New York, p 654

Legendre P (1993) Spatial autocorrelation-trouble or new paradigm. Ecology 74:1659-1673

Legendre P, Fortin MJ (1989) Spatial pattern and ecological analysis. Vegetatio 80:107-138

Levin SA (1989) Challenges in the development of a theory of ecosystem structure and function. In: Roughgarden J, May RM, Levin SA (eds) Perspectives in ecological theory. Princeton Univeristy Press, Princeton, NJ

Levin SA (1992) The problem of pattern and scale in ecology. Ecology 73:1943-1967

McCarty MK (1982) Musk thistle (Carduus thoermeri) seed production. Weed Sci 30:441-445

McCarty MK, Scifres CJ, Smith AL, Horst GL (1969) Germination and early seedling development of musk and plumeless thistles. University of Nebraska, Nebraska, pp 1-28

Medd RW, Smith RCG (1978) Prediction of potential distribution of Carduus-Nutans (Nodding Thistle) in Australia. J Appl Ecol 15:603-612

Moore RJ, Mulligan GA (1956) Natural hybridization between Carduus acanthoides and Carduus nutans in Ontario. Can J Bot 34:71-85

Murrell DJ, Law R (2003) Heteromyopia and the spatial coexistence of similar competitors. Ecol Lett 6:48-59

Pacala SW (1986) Neighborhood models of plant-population dynamics.2. multispecies models of annuals. Theor Popul Biol 29:262-292

Pauchard A, Shea K (2006) Integrating the study of non-native plant invasions across spatial scales. Biol Invasions 8:399-413

Pauchard A, Alaback PB, Edlund EG (2003) Plant invasions in protected areas at multiple scales: linaria vulgaris (Scrophulariaceae) in the west Yellowstone area. West N Am Nat 63:416-428

Poll M, Naylor BJ, Alexander JM, Edwards PJ, Dietz H (2009) Seedling establishment of Asteraceae forbs along altitudinal gradients: a comparison of transplant experiments in the native and introduced ranges. Divers Distrib 15:254-265

Purves DW, Law R (2002) Fine-scale spatial structure in a grassland community: quantifying the plant's-eye view. J Ecol 90:121-129

R Development Core Team (2010) R: A language and environment for statistical computing. Austria: R Foundation for statistical computing, Vienna

Rauschert ESJ (2006) Competitive interactions and associations of the invasive thistles Carduus nutans and $C$. acanthoides. Ph.D. thesis, Intercollege graduate degree program in ecology, The Pennsylvania State University, University Park, p 253

Rhodes AF, Block TA (2000) The plants of Pennsylvania: an illustrated manual. University of Pennsylvania Press, Philadelphia

Seabloom EW, Bjørnstad ON, Bolker BM, Reichman OJ (2005) Spatial signature of environmental heterogeneity, dispersal, and competition in successional grasslands. Ecol Monogr 75:199-214

Shea K, Kelly D (1998) Estimating biocontrol agent impact with matrix models: Carduus nutans in New Zealand. Ecol Appl 8:824-832

Sindel BM (1991) A review of the ecology and control of thistles in Australia. Weed Res 31:189-201

Skarpaas O, Shea K (2007) Dispersal patterns, dispersal mechanisms, and invasion wave speeds for invasive thistles. Am Nat 170:421-430

Skinner K, Smith L, Rice P (2000) Using noxious weed lists to prioritize targets for developing weed management strategies. Weed Sci 48:640-644

Sokal RR, Rohlf FJ (1995) Biometry: the principles and practice of statistics in biological research. W.H. Freeman and Company, New York

Stoll P, Bergius E (2005) Pattern and process: competition causes regular spacing of individuals within plant populations. J Ecol 93:395-403

USDA-NRCS (2010) The PLANTS database (http://plants. usda.gov). Accessed 15 January 2010

Warwick SI, Thompson BK (1989) The mating system in sympatric populations of Carduus-Nutans, C-Acanthoides and their hybrid swarms. Heredity 63:329-337

Warwick SI, Bain JF, Wheatcroft R, Thompson BK (1989) Hybridization and introgression in Carduus-Nutans and Carduus- Acanthoides reexamined. Systematic Botany 14:476-494

Wiens JA (1989) Spatial scaling in ecology. Funct Ecol 3: 385-397

Wilson JB (1988) Community structure in the flora of islands in lake Manapouri, New-Zealand. J Ecol 76:1030-1042

Winston MR (1995) Cooccurrence of morphologically similar species of stream fishes. Am Nat 145:527-545 